\title{
The Prognostic Power of the NOD2 Genotype for Complicated Crohn's Disease: A Meta-Analysis
}

Jeremy Adler, MD, MSc ${ }^{1}$, Sujal C. Rangwalla, $\mathrm{DO}^{1}$, Ben A. Dwamena, MB, ChB ${ }^{2}$ and Peter D.R. Higgins, $\mathrm{MD}, \mathrm{PhD}, \mathrm{MSc}{ }^{3}$

OBJECTIVES: Crohn's disease is often purely inflammatory at presentation, but most patients develop strictures and fistulae over time (complicated disease). Many studies have suggested that nucleotide-binding oligomerization domain 2 (NOD2) mutations are associated with a varying but increased risk of complicated disease. An accurate and sufficiently powerful predictor of complicated disease could justify the early use of biological therapy in high-risk individuals. We performed a systematic review and meta-analysis to obtain accurate estimates of the predictive power of the identified mutations (such as p.R702W, P.G908R, and p.Leu1007fsX1008) in NOD2 for the risk of complicated disease.

METHODS: $\quad$ An electronic search of MEDLINE, Embase, and Web of Science identified 917 relevant papers. Inclusion required specification of genetic mutations at the individual level and disease phenotypes by Vienna classification (inflammatory (B1), stricturing (B2), and fistulizing (B3)). A total of 49 studies met these criteria, which included 8,893 subjects, 2,897 of whom had NOD2 mutations. Studies were weighted by median disease duration. Studies not providing duration data were weighted at the level of the study with the shortest disease duration (3.9 years).

RESULTS: $\quad$ The relative risk (RR) of the presence of any NOD2 mutant allele for complicated disease (B2 or B3) was 1.17 (95\% confidence interval $(95 \% \mathrm{CI}) 1.10-1.24 ; P<0.001)$. P.G908R was associated with an RR of complicated disease of $1.33(95 \% \mathrm{Cl} 1.11-1.60 ; P=0.002)$. NOD2 did not predict perianal disease $(P=0.4)$. The RR of surgery was $1.58(95 \% \mathrm{Cl} 1.38-1.80 ; P<0.001)$. There was substantial heterogeneity across all studies $(R=66.7 \%)$. On the basis of logistic regression of these data, the sensitivity of any mutation in predicting complicated disease was $36 \%$ and specificity was $73 \%$, with the area under the receiver operating characteristic curve 0.56 .

CONCLUSIONS: The presence of a single NOD2 mutation predicted an $8 \%$ increase in the risk for complicated disease (B2 or B3), and a $41 \%$ increase with 2 mutations. Surgery risk is increased by $58 \%$ with any NOD2 mutation, whereas perianal disease was unchanged. The predictive power associated with a single NOD2 mutation is weak. The RR of any NOD2 mutations for complicated disease was only $17 \%$ across 36 studies. However, the presence of two NOD2 mutations had $98 \%$ specificity for complicated disease. These data provide insufficient evidence to support top-down therapy based solely on single NOD2 mutations, but suggest that targeted early-intensive therapy for high-risk patients with two NOD2 mutations might be beneficial, if prospective trials can demonstrate changes in the natural history in this subset of patients.

SUPPLEMENTARY MATERIAL is linked to the online version of the paper at http://www.nature.com/ajg

Am J Gastroenterol advance online publication, 22 February 2011; doi:10.1038/ajg.2011.19

\section{INTRODUCTION}

Crohn's disease is a chronic immune-mediated inflammatory condition of the gastrointestinal tract. Complex interactions between the immune system and the intestinal luminal flora trigger chronic inflammatory responses, which results in the development of intestinal fibrosis over time. Initially, the majority

${ }^{1}$ Division of Gastroenterology, Department of Pediatrics and Communicable Diseases, University of Michigan Health System, Ann Arbor, Michigan, USA; ${ }^{2}$ Division of Nuclear Medicine, Department of Radiology, University of Michigan Health System, Ann Arbor, Michigan, USA; ${ }^{3}$ Division of Gastroenterology, Department of Internal Medicine, University of Michigan Health System, Ann Arbor, Michigan, USA. Correspondence: Jeremy Adler, MD, MSc, Division of Gastroenterology, Department of Pediatrics and Communicable Diseases, University of Michigan Health System, 1150 West Medical Center Drive, A520B MSRB I, Box 5658, Ann Arbor, Michigan 48109, USA. E-mail: jeradler@umich.edu

Received 5 February 2010; accepted 4 January 2011 
of patients develop a purely inflammatory presentation of disease $(1,2)$. However, most patients eventually develop intestinal fibrosis, which leads to the development of severe complications, such as intestinal strictures and fistulae.

The rate at which individuals develop stricturing or penetrating complications varies widely. The rate of progression seems to be unpredictable, although many attempts have been made to define an "aggressive phenotype" (1,3-6). The goal of predicting disease phenotype is to identify patients at risk of more severe disease who may benefit from early aggressive therapy. There are two requisite conditions that must be fulfilled for a predictive strategy to be successful. First, the predictive test must be sensitive and specific for complicated disease. Second, the group predicted to have complicated disease must have a proven response to a cost-effective change in therapy that results in a significant change in the natural history of these patients.

Susceptibility genes for Crohn's disease have been recently elucidated. The first and most promising identified mutations are in the nucleotide-binding oligomerization domain 2 (NOD2), also known as the caspase recruitment domain 15 (CARD15) gene, located on chromosome 16q12. NOD2/CARD15 has been identified as a disease-susceptibility gene, which confers a risk for the development of Crohn's disease (7-12). Many studies have suggested that NOD2 mutations are associated with a varying but increased risk of complicated disease (10,13-15). Certain NOD2 mutations have been postulated to lead to more severe defects and thus predict more aggressive disease behavior $(14,16-18)$. However, published data to date are conflicting as to the prognostic value of NOD2 genotyping (19-21).

Most studies to date have been focused on the risk of disease development, and do not specifically address disease severity. Relatively few studies have directly investigated the question of disease severity, although some of the large disease-susceptibility studies contain information on disease phenotype and severity. Published studies of disease phenotype have demonstrated varying degrees of risk attributable to NOD2 mutations $(19,20)$. Some papers have focused on differences between specific NOD2 mutations, whereas others have focused on numbers of mutant alleles (10,22-24).

Predictive results vary widely across these studies. For genotyping patients to be useful in practice, an estimation of the risk of severe disease associated with a genotype would have to be clearly defined. If a method of predicting disease severity was accurate, the benefits to patient care would be tremendous. An accurate and sufficiently powerful predictor of complicated disease, followed by targeted, cost-effective intervention for these patients could potentially change the natural history of Crohn's disease, and justify early use of expensive biological therapies in high-risk individuals.

Three major polymorphisms in the NOD2 gene have been reported to be associated with Crohn's disease. These singlenucleotide polymorphisms include p.R702W, p.G908R, and p.Leu1007fsX1008. We performed a systematic review of the literature with meta-analysis to obtain accurate estimates of the predictive power of these identified mutations (p.R702W, p.G908R, and p.Leu1007fsX1008) in NOD2 for the risk of complicated disease. Other minor alleles have been reported, and where sufficient data exist, we attempted to include these data as well. We defined complicated disease as stricturing and/or fistulizing Crohn's disease for the purposes of this study.

\section{METHODS}

\section{Search strategies}

This systematic review of the literature and meta-analysis was performed and reported according to standard guidelines for systematic review and meta-analysis of diagnostic studies (25-28). We conducted a computer-aided literature search of MEDLINE database (Ovid Technologies, New York, NY) from inception to 31 December 2009. The search strategy used free-text words and MeSH terms (("genotype/" or "genotype.mp" or nod2 or card15 or "Nod2 Signaling Adaptor Protein/") and ("exp Crohn Disease/" or "exp Inflammatory Bowel Diseases/") and ("Phenotype/" or "phenotype.mp" or "exp Intestinal Obstruction/" or "Constriction, Pathologic/" or "stenosis.mp" or "stricture.mp" or "fibrostenosing.mp" or "stricturing.mp" or "exp Fistula/" or "exp Intestinal Fistula/" or "exp Digestive System Fistula/" or "exp Fistula/" or "exp Gastric Fistula/" or "exp Rectovaginal Fistula/" or "exp Rectal Fistula/" or "penetrating.mp")) to increase the sensitivity of the search strategy (29).

We conducted an additional computer-aided literature search of the Embase database (Elsevier, New York, NY) from inception to 31 December 2009. The search strategy was as follows: ((nod2 or card15) and (stricture or stricturing or 'fistula'/exp or fistula or fistulizing or penetrating or 'phenotype'/exp or phenotype or 'stenosis'/exp or stenosis) and ('crohn disease'/exp or 'crohn disease' or 'regional enteritis'/exp or 'regional enteritis')).

The search was not restricted to English-language publications. In addition, after study selection, we reviewed the bibliographies of the studies to identify any additional studies relevant to this topic. Additional searches through ISI Web of Science (Thomson Reuters, New York, NY) and Google Scholar (Google, Mountain View, CA) were performed to identify any additional publications that may have been missed with the aforementioned searches.

\section{Study selection}

Two independent reviewers (J.A. and S.C.R.) read the titles of all candidate articles. For those articles that were not excluded based solely on the title, we reviewed the abstract. We then retrieved the full text of published manuscripts that could not be excluded based on the title and abstract alone. The articles were read and checked for inclusion criteria independently. All discrepancies were resolved by consensus. The final agreement between reviewers was $100 \%$ for study selection.

\section{Study inclusion/exclusion criteria}

The selection criteria for inclusion of a study were: (i) clear statement of disease definition; (ii) clear statement of genotyping and which mutations were studied; (iii) classification of disease phenotype by Vienna or Montreal classification with non-overlapping phenotypes $(6,30)$; (iv) documentation of genotype by phenotype on individual level data (not population gene frequency data); and (v) if raw numbers of each genotype-phenotype combination could be found or clearly calculated from the published data. 
Exclusion criteria were: (i) duplicate publications of a primary study that contained all or a subset of the original data; (ii) studies presenting only gene frequency data; and (iii) studies involving patients with ulcerative colitis or indeterminate colitis. In cases of potential or suspected overlapping subject populations (based either on location or authorship), the latest publication or the study with the largest numbers of patients was included in the meta-analysis. All others were excluded.

\section{Data extraction}

Two independent reviewers (J.A. and S.C.R.) extracted the following data from the selected studies onto data abstraction forms: study characteristics (such as design, country, year of publication, setting/region, sample size, phenotype data, genotype data, age at diagnosis, disease duration), population (mean age, sex, number of patients with each disease phenotype, criteria for diagnosis, genotyping technique, criteria for definition of phenotype), and outcomes (numbers of each NOD2 allele mutation and genotype-phenotype combinations). Other variables that were sought included methods for handling indeterminate or missing data. Discrepancies were resolved by discussion and consensus with the senior author (P.D.R.H.). We included two Spanishlanguage papers because one author (J.A.) is literate in Spanish. We excluded one Polish, two Hungarian, and one German language paper as we had no available resources to assist in translation.

After completion of manuscript review and data extraction, all included studies were reviewed for assessment of study quality. Manuscripts were assessed according to a modified subset of the QUADAS (Quality Assessment Tool for Diagnostic Accuracy) guidelines (31).

\section{Statistical analysis}

The primary outcome for this analysis was the diagnostic test performance of NOD2 genotyping for predicting Crohn's disease phenotype. We applied the bivariate random-effects regression model for treatment trial meta-analysis and modified for synthesis of diagnostic test data assuming a binomial error distribution for sensitivity and specificity $(32,33)$. Sensitivity, specificity, and diagnostic odds ratios with 95\% confidence intervals (95\% CIs) were calculated. The diagnostic odds ratio is defined as the odds of having a positive test result (mutant allele present) in patients with disease finding (fistulizing disease, etc.) compared with the odds of a positive test result in patients without the disease (no fistulizing disease). The diagnostic odds ratio is a single indicator of test accuracy that combines data from sensitivity and specificity (34).

The heterogeneity of the results between the studies was assessed graphically by forest plots, and statistical assessment was performed with the $\chi^{2}$ test of homogeneity and the inconsistency index $\left(I^{2}\right)$ and Cochran's $Q$-test for non-combinability. The $I^{2}$ index describes the percentage of total variation across studies that are due to heterogeneity rather than chance. A value between 50 and 75 represents moderate heterogeneity (35). A non-significant Cochrane $Q$ represents minimal heterogeneity, indicating that the studies can be combined.

The overall performance of NOD2 was assessed with summary receiver operating characteristic (ROC) curve. We analyzed the data using the midas (Meta-analytical Integration of Diagnostic Accuracy Studies) command (36,37). All statistical analyses were performed using Stata 11.0 for Mac (StataCorp LP, College Station, TX).

\section{RESULTS}

\section{Literature search}

The results of the literature search are summarized in Figure 1. Two independent reviewers (J.A. and S.C.R.) identified abstracts and titles of 917 studies for initial review based on the described search strategies. A total of 357 studies were chosen for detailed review, and 49 studies that met the inclusion and exclusion criteria were included in the meta-analysis. There was 100\% agreement between reviewers on the selection of studies.

\section{Excluded studies}

Upon review of the title and abstract, 560 studies were excluded for not meeting the pre-specified inclusion criteria. An additional 308 studies were excluded after full review of the published manuscript. Upon full review of the manuscripts, 96 were identified as not being studies of Crohn's disease. A total of 84 studies investigated other genetic mutations than those of NOD2/CARD15. In all, 34 studies were excluded for lack of phenotypic information. An additional 95 studies were excluded for inadequate documentation of genotype-phenotype combinations. Overall, 58 studies were excluded for not providing original data, being individual case reports, review articles, commentaries, or small meta-analyses. Six manuscripts contained incomplete or inconsistent data. An additional 18 studies included only gene frequency or otherwise did not include patient level data. One paper was excluded as it was a single patient case report.

\section{Included studies}

A total of 49 studies included in this meta-analysis comprised 8,893 patients with Crohn's disease, of whom 2,897 had NOD2 mutations (Table 1). Of the 33 studies documenting disease duration, these data included 64,955 patient-years of disease duration. Studies were weighted by median disease duration. The 16 studies not providing disease duration data were weighted at the level of the study with the shortest documented median disease duration (3.9 years).

\section{Quality assessment}

The selection criteria were clearly documented in 10 out of 49 studies. The description of phenotype was clearly documented in 12 studies. The description of the method for genotyping was present in all but six papers. The spectrum of patients was generally reflective of clinical practice, except in four papers. Explicit documentation of how missing data were handled was present in only two papers, whereas eight papers clearly had missing data that were unaccounted for. Only 11 papers included documentation that those assessing phenotypes were blinded to the results of genotyping. A summary of the QUADAS criteria is depicted in Supplementary Figure 1 online. 


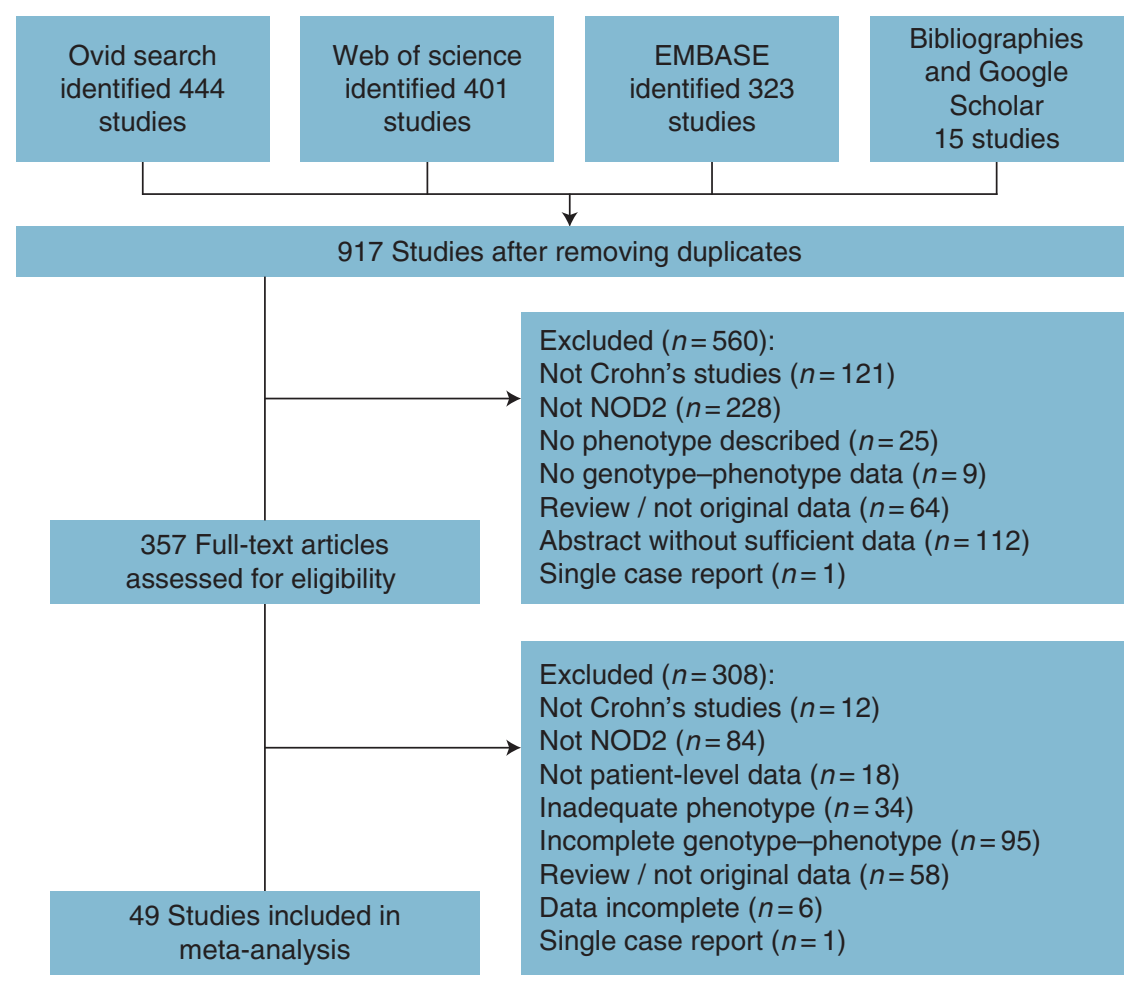

Figure 1. Flow diagram of studies identified in the systematic review and meta-analysis. NOD2, nucleotide-binding oligomerization domain 2.

All studies included were assessed for quality. Specific items assessed included the presence of a clear description of selection criteria. The description of phenotyping was recorded as the reference standard.

\section{Risk of complicated disease}

The risk of complicated disease (stricturing or fistulizing) was compared between patients with various predetermined combinations of NOD2 mutations (Table 2). The pooled relative risk (RR) of complicated disease with the presence of any (one or more) NOD2 mutant allele was 1.17 (95\% CI 1.10-1.24; $P<0.001$; Figure 2a) across 36 studies with a total of 6,115 patients. There was moderate evidence of heterogeneity between studies $\left(I^{2}=66.7 \%\right.$; Cochran's $Q$ 59.7, $P=0.003)$. Study-specific sensitivities are shown in Figure 2b, with a pooled sensitivity of 0.36 (95\% CI 0.31-0.40) and a specificity of 0.73 (95\% CI 0.69-0.77).

A dose effect was seen with the presence of one NOD2 mutant allele (see Supplementary Figure 2 online) associated with an RR of complicated disease of 1.08 (95\% CI 0.96-1.21; $\left.P=0.2 ; I^{2}=44.6 \% ; Q=18.4, P=0.05\right)$ across 13 studies, whereas the presence of 2 NOD2 mutant alleles (see Supplementary Figure 3 online) had an RR of 1.41 (95\% CI 1.26-1.57; $P<0.001$; $\left.I^{2}=55.0 \% ; Q=12.5, P=0.2\right)$ with a sensitivity of $0.11(95 \%$ CI $0.06-0.21)$ and a specificity of 0.98 (95\% CI $0.92-0.99)$ for complicated disease. The presence of homozygous mutations of NOD2 was associated with an RR of complicated disease of 1.45 (95\% CI 1.31-1.61; $P<0.001 ; I^{2}=93.8 \% ; Q=4.5, P=0.2$ ), with a sensitivity of $0.05(95 \%$ CI $0.01-0.16)$ and a specificity of
1.00 (95\% CI 0.94-1.00) across 7 studies (see Supplementary Figure 4 online).

When specific individual mutant alleles were assessed, p.G908R was the only allele found to have a significant association with complicated disease. In 10 studies with sufficient data to assess its affect, p.R702W was found to confer an RR of complicated disease of 1.11 (95\% CI 0.92-1.36; $P=0.3 ; I^{2}=67.2 \% ; Q=18.3, P=0.02$ ), with a sensitivity of 0.28 ( $95 \%$ CI $0.09-0.62)$ and a specificity of 0.86 (95\% CI 0.79-0.91). In 10 studies, p.G908R was found to be associated with an RR of complicated disease of 1.33 (95\% CI 1.11-1.60; $P=0.002 ; I^{2}=34.4 \% ; Q=9.0, P=0.3$ ) with a sensitivity of $0.1(95 \% \mathrm{CI}$ $0.07-0.13$ ) and a specificity of 0.93 ( $95 \%$ CI $0.88-0.96)$. In 13 studies, p.Leu1007fsX1008 was associated with an RR of complicated disease of 1.07 (95\% CI 0.94-1.21; $P=0.3 ; I^{2}=66.4 \% ; Q=25.0, P=0.009$ ) with a sensitivity of $0.31(95 \%$ CI $0.11-0.63)$ and a specificity of 0.89 (95\% CI 0.84-0.92) (see Supplementary Figure 5 online).

When homozygous mutations were assessed for individual mutant alleles, p.Leu1007fsX1008 was the only allele found to have a significant association with complicated disease. In 3 studies, p.R702W was found to confer an RR of complicated disease of 1.18 (95\% CI 0.31-4.57; $P=0.81 ; I^{2}=0.0 \% ; Q=0.02, P=0.88$ ). In 3 studies, p.G908R was found to confer an RR of complicated disease of 1.70 (95\% CI 0.77-3.76; $P=0.19 ; I^{2}=0.0 \% ; Q=0.09$, $P=0.76$ ). In 5 studies, p.Leu1007fsX1008 was found to be associated with an RR of complicated disease of 1.30 (95\% CI 1.10-1.54; $\left.P=0.002 ; I^{2}=17.6 \% ; Q=3.21, P=0.36\right)$ with a sensitivity of 0.03 (95\% CI 0.01-0.11) and a specificity of 0.99 (95\% CI $0.96-100)$ $(23,38-41)$. 
Table 1. Study characteristics

\begin{tabular}{|c|c|c|c|c|}
\hline Author & Year & Country & Number of patients & Median duration of disease (years) \\
\hline Alvarez-Lobos et al. (48) & 2007 & Spain & 170 & 6 \\
\hline Brant et al. (50) & 2003 & USA & 214 & 14.9 \\
\hline Bianchi et al. (51) & 2007 & Italy & 177 & 8.5 \\
\hline Canto et al. (53) & 2007 & Spain & 97 & NR \\
\hline Chua et al. (41) & 2009 & Malaysia & 45 & NR \\
\hline Crawford et al. (40) & 2007 & USA & 205 & 4.6 \\
\hline Cucchiara et al. (54) & 2007 & Italy & 196 & 9 \\
\hline de Ridder et al. (58) & 2007 & The Netherlands & 72 & NR \\
\hline Esters et al. (59) & 2004 & Belgium & 344 & NR \\
\hline Fernandez et al. (60) & 2004 & Spain & 210 & 9.9 \\
\hline Ferreira et al. (61) & 2005 & Portugal & 231 & 9.7 \\
\hline Fidder et al. (62) & 2003 & Israel & 170 & NR \\
\hline Giachino et al. (63) & 2004 & Italy & 184 & NR \\
\hline Heresbach et al. (64) & 2004 & France & 205 & 7.1 \\
\hline Hsiao et al. (65) & 2007 & Taiwan & 10 & 4.7 \\
\hline Maconi et al. (71) & 2009 & Italy & 253 & 14.4 \\
\hline Mardini et al. (39) & 2005 & USA & 202 & 7.1 \\
\hline Marrakchi et al. (72) & 2009 & Tunesia & 75 & NR \\
\hline Mendoza et al. (73) & 2003 & Spain & 204 & 8 \\
\hline Protic et al. (74) & 2008 & Serbia & 131 & 7 \\
\hline Radlmayr et al. (75) & 2002 & Germany & 97 & NR \\
\hline Rigoli et al. (76) & 2008 & Italy & 133 & NR \\
\hline Rodrigo et al. (77) & 2007 & Spain & 183 & 12 \\
\hline Sabate et al. (78) & 2008 & France & 239 & 9.3 \\
\hline Schoepfer et al. (79) & 2009 & Switzerland & 252 & NR \\
\hline Seiderer et al. (38) & 2006 & Germany & 299 & 10.5 \\
\hline Shaoul et al. (80) & 2009 & Israel & 125 & 3.9 \\
\hline Smith et al. (81) & 2004 & Scotland & 143 & 5 \\
\hline Sun et al. (82) & 2003 & Germany & 55 & NR \\
\hline Tekin et al. (83) & 2009 & Turkey & 45 & NR \\
\hline
\end{tabular}


Table 1. Continued

\begin{tabular}{|c|c|c|c|c|}
\hline Author & Year & Country & Number of patients & Median duration of disease (years) \\
\hline Törkvist et al. (85) & 2006 & Sweden & 179 & 16.5 \\
\hline van der Linde et al. (86) & 2007 & The Netherlands & 114 & NR \\
\hline Vavassori et al. (23) & 2004 & Italy & 165 & 12.0 \\
\hline Vermeire et al. (87) & 2002 & Quebec & 229 & NR \\
\hline Total & & & 8,883 & \\
\hline
\end{tabular}

NR, not reported.

\section{Risk of stricturing disease}

The risk of stricturing disease was compared between patients with various predetermined combinations of NOD2 mutations. The pooled RR of stricturing disease with the presence of any (one or more) NOD2 mutant allele was 1.33 (95\% CI 1.15-1.55; $P<0.001$; Figure 3a) across 35 studies. There was moderate evidence of heterogeneity between studies $\left(I^{2}=67.5 \%\right.$; Cochran's $Q$ $71.5, P=0.001)$. Study-specific pooled sensitivities and specificities included a sensitivity of 0.39 (95\% CI $0.34-0.45)$ and a specificity of 0.73 (95\% CI 0.68-0.76). In 12 studies in which there were sufficient data to consider individual mutations, p.G908R was found to be associated with an RR of stricturing disease of 1.90 (95\% CI 1.17-3.07; $P=0.009 ; I^{2}=56.1 \% ; Q=8.82, P=0.27$ ) with a sensitivity of 0.11 (95\% CI $0.07-0.16)$ and a specificity of 0.94 (95\% CI 0.89-97). There was no attributable risk for stricturing disease with either p.R702W $(P=0.5)$ or p.Leu1007fsX1008 $(P=0.95)$ mutations.

\section{Risk of fistulizing disease}

The risk of fistulizing disease was compared between patients with various predetermined combinations of NOD2 mutations. The pooled RR of fistulizing disease with the presence of any (one or more) NOD2 mutant allele was 1.16 (95\% CI 1.05-1.28; $P<0.003$; Figure $3 \mathbf{b}$ ) across 36 studies. There was little evidence of heterogeneity between studies $\left(I^{2}=27.3 \%\right.$; Cochran's $\left.Q 38.2, P=0.3\right)$. Studyspecific sensitivities and specificities included a sensitivity of 0.34 (95\% CI 0.30-0.38) and a specificity of 0.73 (95\% CI 0.69-0.76). In 9 studies, p.G908R was found to be associated with an RR of fistulizing disease of 1.42 (95\% CI 1.06-1.90; $P=0.02 ; I^{2}=26.2 \%$; $Q=8.69, P=0.28)$ with a sensitivity of 0.08 (95\% CI $0.05-0.12$ ) and a specificity of 0.94 (95\% CI 0.89-96). In 12 studies, there was no attributable risk for fistulizing disease with p.R702W $(P=0.13)$ or p.Leu1007fsX1008 $(P=0.66)$ mutations.

\section{Risk of perianal disease}

Perianal disease was reported separately from stricturing or fistulizing phenotype in 17 manuscripts (3,836 patients). When this end point was analyzed, there was no increased or decreased risk of perianal disease associated with the presence of any NOD2 mutant alleles (RR 1.03; 95\% CI 0.92-1.16; $P=0.6 ; I^{2}=52.9 \%$; $Q=33.6, P=0.004$; Figure $4 a)$, with a pooled sensitivity of 0.38 (95\% CI $0.32-0.43)$ and a specificity of 0.63 (95\% CI 0.59-0.66). However, when individual mutations were considered, p.G908R was found to have a slightly decreased risk of perianal disease. In 4 studies (RR 0.40; 95\% CI 0.19-0.83; $P=0.014 ; I^{2}=61.7 \%$; $Q=4.4$, $P=0.1)$, there was no attributable risk for perianal disease with either p.R702W $(P=0.3)$ or p.Leu1007fsX1008 $(P=0.5)$ mutations (see Supplementary Figure 6 online).

\section{Risk of surgery}

The risk of patients undergoing any surgery specifically for Crohn's disease was reported in 17 studies including 3,643 patients. The risk of surgery was found to be increased if one or more NOD2 mutant alleles were present (RR 1.58; 95\% CI 1.38-1.80; $P<0.001$; $I^{2}=63.7 \% ; Q=31.0, P=0.009$; Figure $4 \mathbf{b}$ ) with a pooled sensitivity of 0.41 (95\% CI $0.34-0.48)$ and a specificity of 0.74 (95\% CI $0.69-$ 0.78 ). There were only three studies with complete documentation of single NOD2 mutant alleles and surgical data and an additional seven studies with partial data. The risk of surgery was found to be increased if one NOD2 mutant allele was present $(\mathrm{RR}=1.48$; 95\% CI 1.25-1.75) with a sensitivity of 0.31 (95\% CI $0.27-0.35$ ), a specificity of 0.82 (95\% CI $0.76-0.87)$, and area under the summary ROC (AuROC) 0.53 (95\% CI 0.50-0.56). There were only two studies with complete data documenting the presence of two NOD2 mutant alleles and surgical data and an additional nine studies with partial data. The risk of surgery with two mutant alleles was increased (RR 1.49; 95\% CI 1.16-1.87) with a sensitivity of 0.17 (95\% CI $0.10-0.28)$ and a specificity of 0.90 (95\% CI 0.34-0.99) with an AuROC of 0.27 (95\% CI 0.24-0.30).

\section{Diagnostic accuracy}

The summary statistics for the prognostic value of NOD2 mutations for complicated disease are listed in Table 3. The sensitivity of NOD2 mutations for developing stricturing or fistulizing disease was 0.36 (95\% CI $0.31-0.40)$. The specificity of NOD2 mutations for complicated disease was 0.73 (95\% CI 0.69-0.77). The positive likelihood ratio (LR) of the presence of NOD2 being associated with complicated disease was 1.3 (95\% CI 1.2-1.5); the negative 
Table 2. NOD2 mutant alleles and complicated disease

\begin{tabular}{|c|c|c|c|c|c|c|c|}
\hline Author & Num & TP & FP & FN & $\mathrm{TN}$ & Sens & Spec \\
\hline Annese et al. (49) & 316 & 86 & 60 & 65 & 105 & 57.0 & 63.6 \\
\hline Brant et al. (50) & 214 & 76 & 17 & 78 & 43 & 49.4 & 71.7 \\
\hline Canto et al. (53) & 97 & 17 & 13 & 43 & 24 & 28.3 & 64.9 \\
\hline Chua et al. (41) & 45 & 9 & 5 & 21 & 10 & 30.0 & 66.7 \\
\hline Cukovic-Cavka et al. (55) & 136 & 23 & 15 & 51 & 47 & 31.1 & 75.8 \\
\hline Dassopoulos et al. (56) & 183 & 7 & 6 & 86 & 70 & 7.5 & 92.1 \\
\hline De Diego et al. (57) & 183 & 29 & 21 & 57 & 76 & 33.7 & 78.4 \\
\hline Esters et al. (59) & 344 & 119 & 36 & 138 & 51 & 46.3 & 58.6 \\
\hline Giachino et al. (63) & 184 & 41 & 19 & 62 & 58 & 39.8 & 75.3 \\
\hline Heresbach et al. (64) & 205 & 57 & 21 & 67 & 59 & 46.0 & 73.8 \\
\hline Hsiao et al. (65) & 10 & 0 & 0 & 4 & 6 & 0 & 100 \\
\hline Laghi et al. (66) & 239 & 71 & 8 & 117 & 43 & 37.8 & 84.3 \\
\hline Lappalainen et al. (68) & 240 & 34 & 12 & 113 & 81 & 23.1 & 87.1 \\
\hline Linskens et al. (69) & 108 & 19 & 4 & 50 & 35 & 27.5 & 89.7 \\
\hline Louis et al. (70) & 101 & 21 & 25 & 32 & 23 & 39.6 & 47.9 \\
\hline Maconi et al. (71) & 253 & 98 & 4 & 156 & 6 & 35.8 & 60.0 \\
\hline Shaoul et al. (80) & 125 & 13 & 33 & 13 & 58 & 50.0 & 63.7 \\
\hline Smith et al. (81) & 143 & 9 & 23 & 34 & 77 & 20.9 & 77.0 \\
\hline Sun et al. (82) & 55 & 25 & 11 & 11 & 8 & 69.4 & 42.1 \\
\hline Tekin et al. (83) & 45 & 4 & 7 & 11 & 23 & 26.7 & 76.7 \\
\hline Tomer et al. (84) & 101 & 4 & 25 & 17 & 55 & 19.0 & 68.8 \\
\hline Törkvist et al. (85) & 179 & 11 & - & 36 & - & 23.4 & - \\
\hline van der Linde et al. (86) & 114 & 40 & 8 & 42 & 24 & 48.8 & 75.0 \\
\hline Vermeire et al. (87) & 229 & 58 & 45 & 60 & 66 & 49.2 & 59.5 \\
\hline Vind et al. (88) & 87 & 14 & 5 & 31 & 37 & 31.1 & 88.1 \\
\hline Total & 6,115 & 1,369 & 664 & 2,259 & 1,664 & - & - \\
\hline
\end{tabular}

FN, false negative; FP, false positive; NOD2, nucleotide-binding oligomerization domain 2; Num, number of patients; Sens, sensitivity; Spec, specificity; TN, true negative; TP, true positive.

LR was 0.88 (95\% CI 0.84-0.93). A positive LR of $>10$ and a negative LR of $<0.1$ are generally considered useful predictors. As a prognostic indicator, NOD2 is a poor predictor of the complicated disease phenotype (Figure 5a). 
a

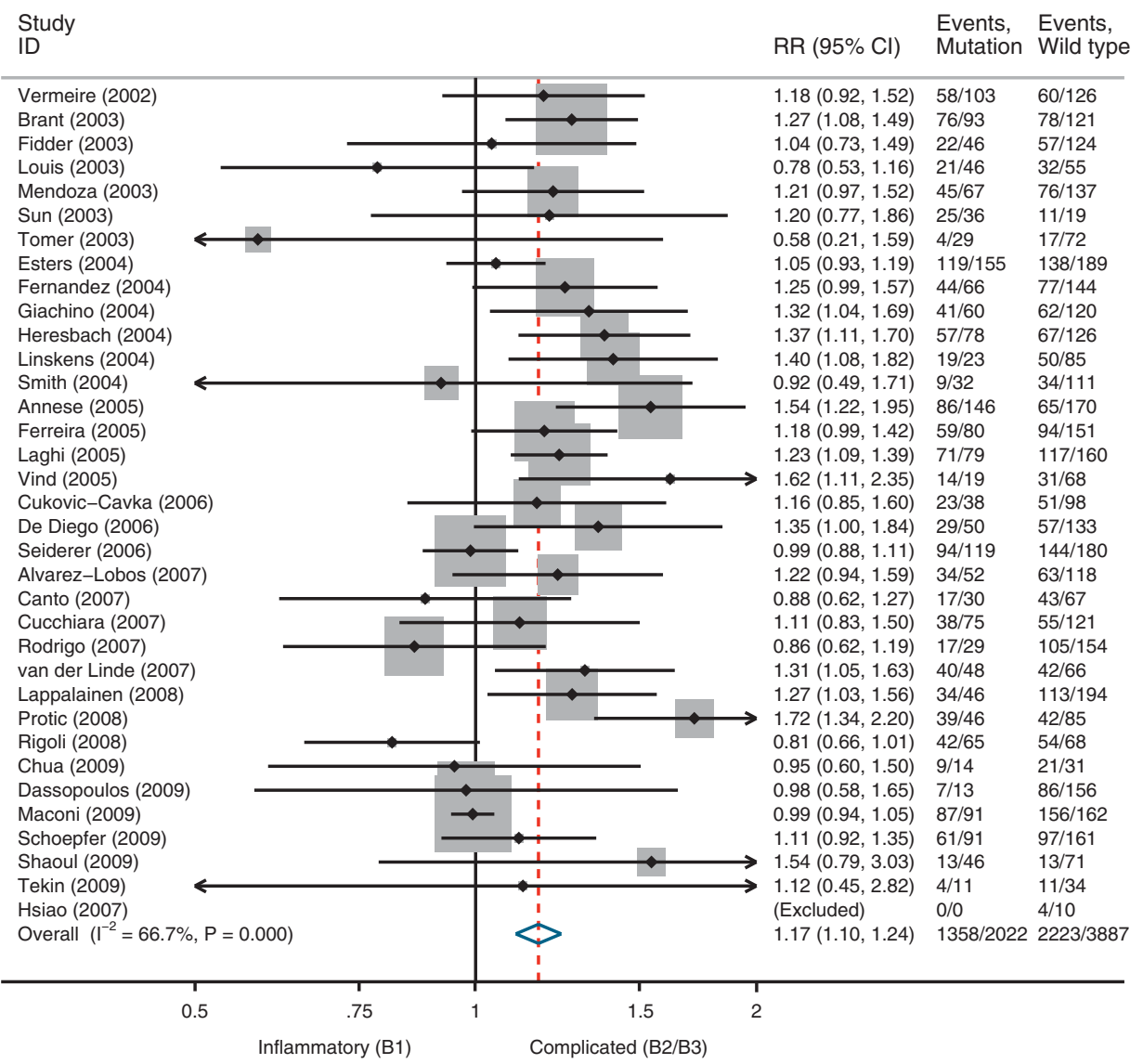

b

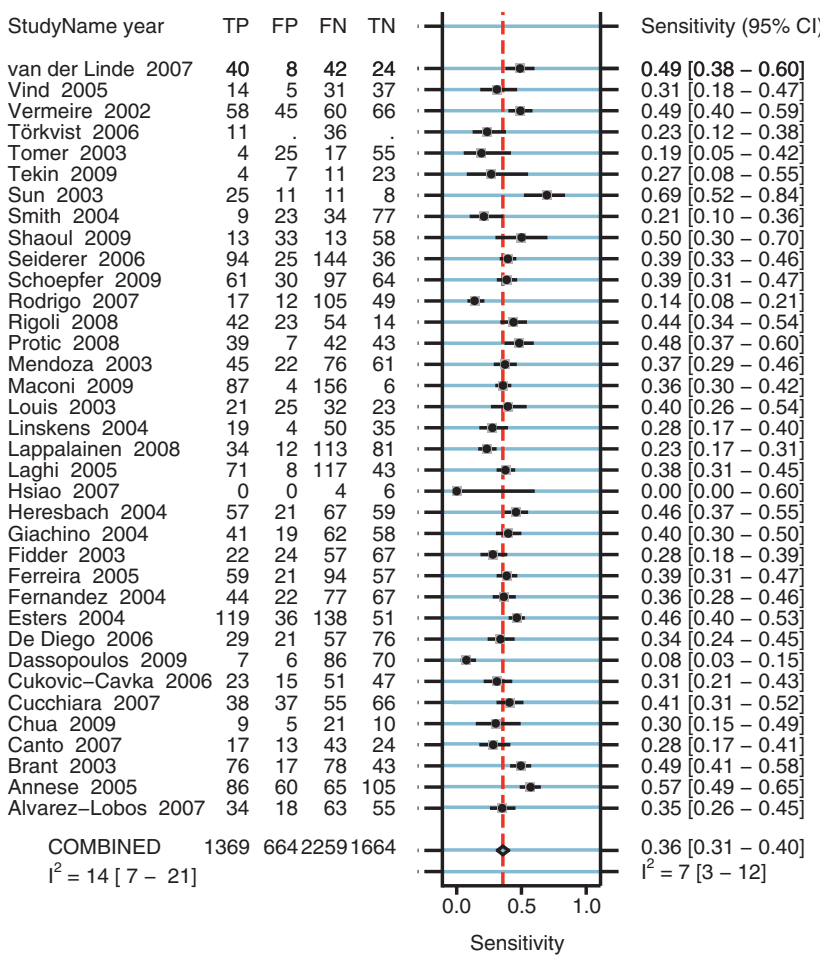

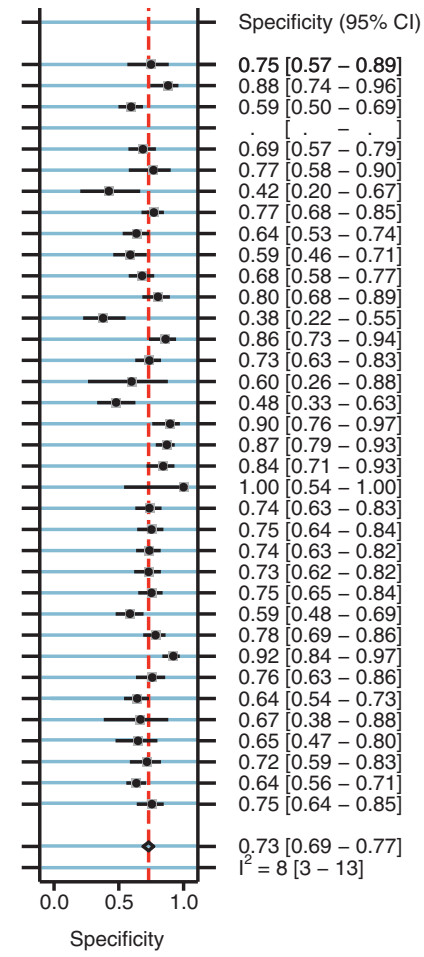

Figure 2. Forest plots of NOD2 and complicated disease. (a) Forest plot of NOD2 mutant alleles and complicated disease showing study relative risk (RR) and 95\% confidence interval $(95 \% \mathrm{Cl}$ ) of complicated disease. There was moderate heterogeneity between studies ( $R=66.7 \%$; Cochran's $Q 59.7, P=0.003)$. Study-specific mean sensitivity (left axis) and specificity (right axis) are shown in b. FN, false negative; FP, false positive; NOD2, nucleotide-binding oligomerization domain 2; TN, true negative; TP, true positive. 
a

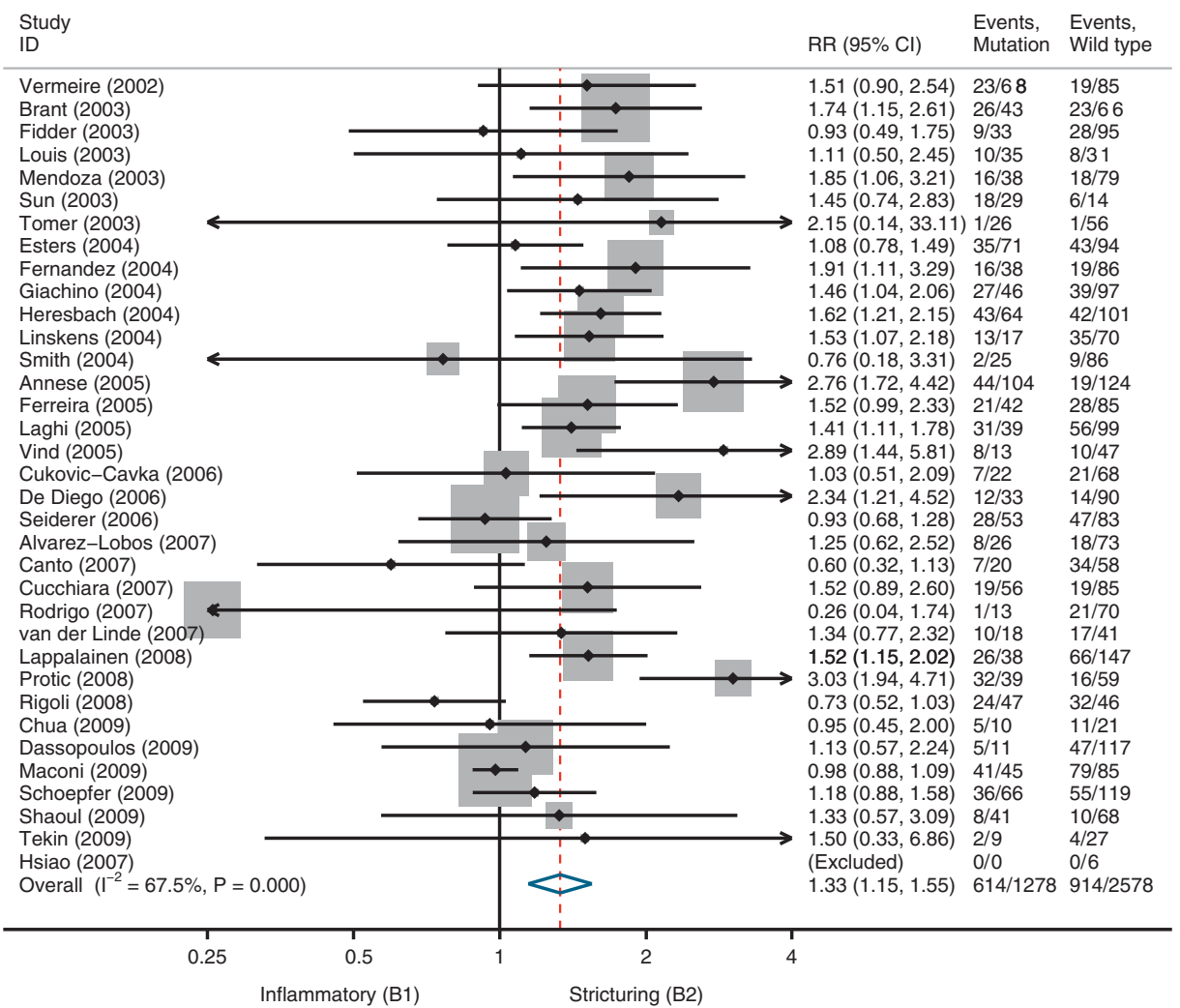

b \begin{tabular}{ll} 
Study & \\
ID & Events, Events, \\
\hline
\end{tabular}

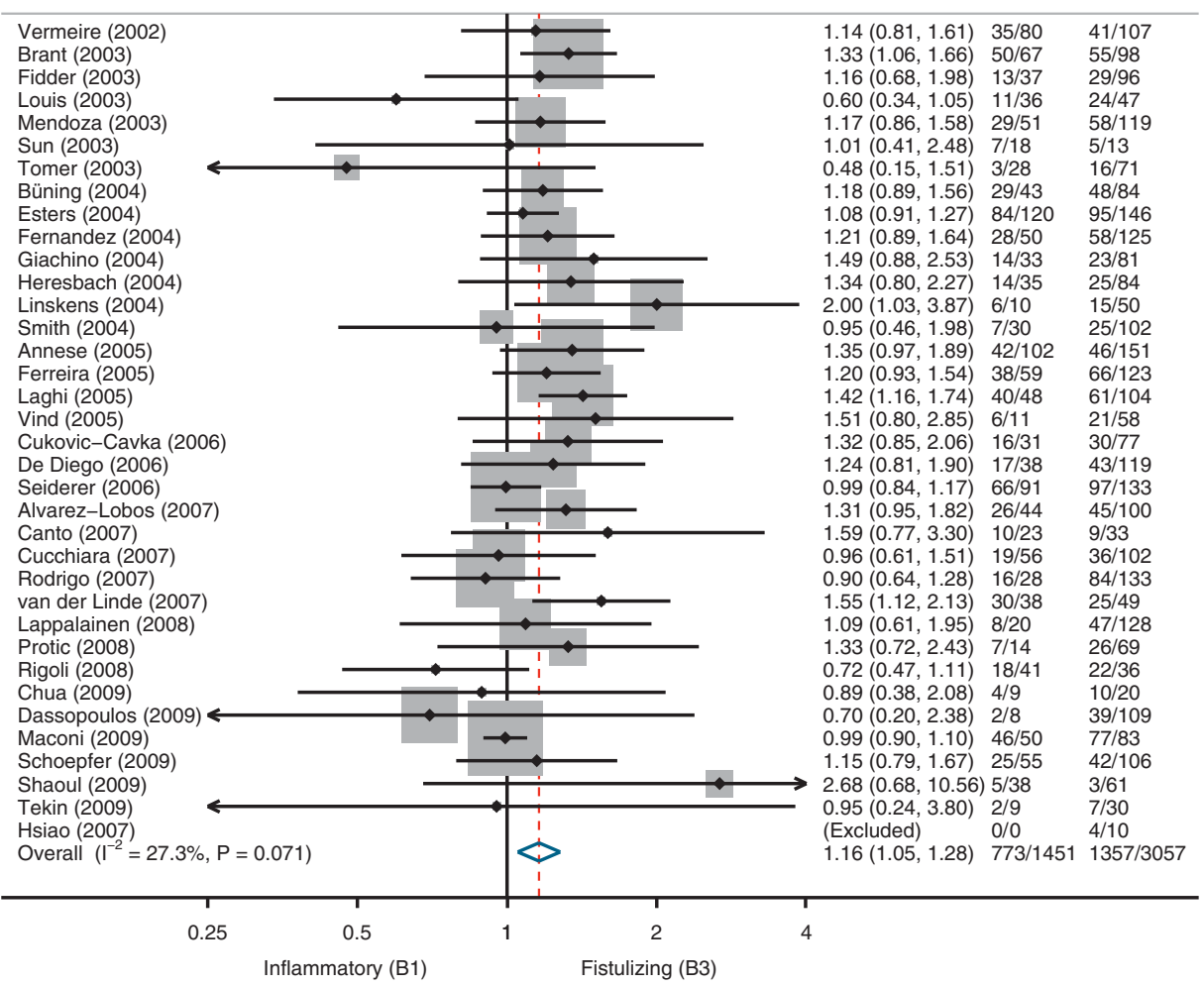

Figure 3. Forest plots of NOD2 and stricturing and fistulizing disease. Forest plot of the presence of one or more NOD2 mutant alleles predicting (a) stricturing disease and (b) fistulizing disease for Crohn's disease. B1, inflammatory; B2, structuring; B3, fistulizing phenotypes; NOD2, nucleotide-binding oligomerization domain 2; RR, risk ratio; 95\% Cl, 95\% confidence interval. 


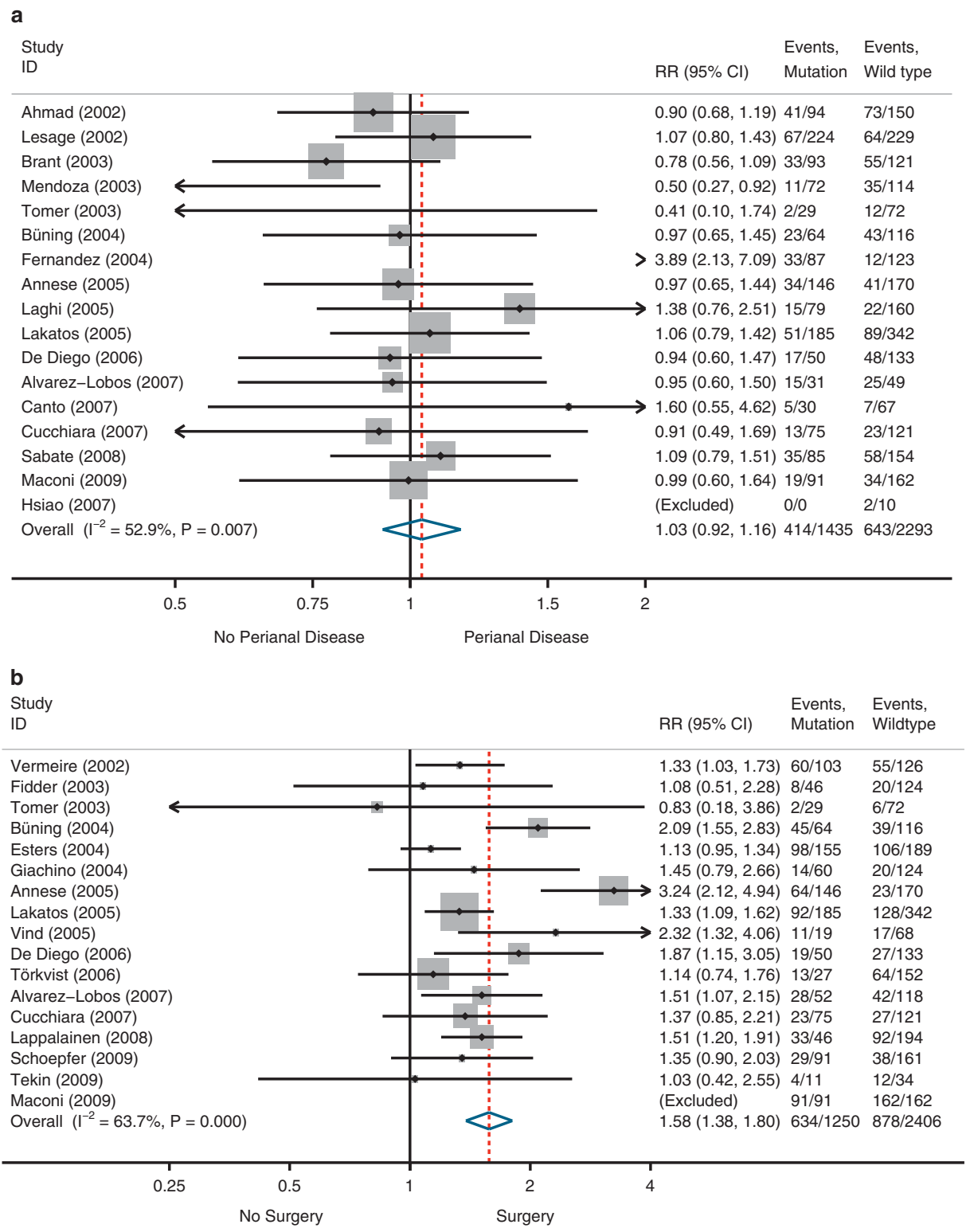

Figure 4. Forest plots of NOD2 and perianal diseases and surgery. Forest plot of the presence of one or more NOD2 mutant alleles predicting (a) perianal disease and (b) any surgery for Crohn's disease. RR, risk ratio; Cl, confidence interval, B1, inflammatory; B2, structuring; B3, fistulizing phenotypes. B1, inflammatory; B2, structuring; B3, fistulizing phenotypes; NOD2, nucleotide-binding oligomerization domain 2; RR, risk ratio; 95\% Cl, 95\% confidence interval.

\section{Effect of diagnostic threshold}

The sensitivity and specificity of the presence of any NOD2 mutant alleles for complicated disease in each study are displayed on the summary ROC diagram. The summary ROC curve and the summary operating point (with $95 \%$ confidence contour) are shown in relation to the individual studies. It must be noted that a coin flip has a diagnostic accuracy of 0.5. The AuROC was 0.56 for complicated disease (Figure 5b) and 0.54 for perianal disease, consistent with low diagnostic accuracy. The AuROC for stricturing disease was 0.61, the AuROC for fistulizing disease was 0.54 , and the AuROC was 0.63 for surgery for Crohn's disease all of which represent poor diagnostic accuracy (see Supplementary Figure 7 online). The AuROC was 0.98 for p.Leu1007fsX1008 homozygous mutations predicting complicated disease. This represents excellent diagnostic accuracy; however, the positive LR is 2.6 (95\% CI 0.4-16.6), and the negative LR is 0.98 (95\% CI 0.94-1.03) (see Supplementary Figure 8 online).

\section{DISCUSSION}

NOD2/CARD15 was identified to be associated with Crohn's disease. There is abundant evidence supporting NOD2 as a susceptibility allele conferring risk for developing Crohn's disease. As the early studies of NOD2, and with the later advent of other genes associated with Crohn's disease, interest has grown toward identifying specific mutations that may be responsible for distinct disease behavior phenotypes. 


\begin{tabular}{|c|c|c|}
\hline Parameter & Estimate & $\begin{array}{l}\text { 95\% confidence } \\
\text { interval }\end{array}$ \\
\hline Sensitivity & 0.36 & $0.31-0.40$ \\
\hline Specificity & 0.73 & $0.69-0.77$ \\
\hline Positive likelihood ratio & 1.3 & $1.2-1.5$ \\
\hline $\begin{array}{l}\text { Negative likelihood } \\
\text { ratio }\end{array}$ & 0.88 & $0.84-0.93$ \\
\hline Diagnostic odds ratio & 1 & $1-2$ \\
\hline \multicolumn{3}{|c|}{ NOD2, nucleotide-binding oligomerization domain 2.} \\
\hline \multicolumn{3}{|c|}{$\begin{array}{l}\text { Summary estimates for all the studies for any NOD2 mutation predicting } \\
\text { complicated (stricturing or fistulizing) disease. }\end{array}$} \\
\hline
\end{tabular}

There have been conflicting reports from early in the literature as to the prognostic value of NOD2. Abreu et al. (10) in 2002 found that NOD2 mutations were specifically associated with fibrostenosing disease and not penetrating disease. That same year, Lesage et al. (24), found no association between NOD2 mutations and specific disease phenotypes. Alvarez-Lobos et al. (13) and Ince et al. (21) showed an association between NOD2 mutations and increased surgical rates in Crohn's disease, whereas Baptista et al. (19) found no measurable associations with disease behavior could be detected at all.

There have been a number of small meta-analyses that have looked to answer these questions, but no full review of the literature to date exists $(22,42,43)$. We undertook a full systematic review of the published literature to gain a better understanding as to how the presence of NOD2 mutations modifies disease behavior.

This meta-analysis showed that the presence of a single NOD2/ CARD15 mutation has poor predictive ability for disease phenotype in Crohn's disease with an AuROC of 0.56. Summary estimates showed poor sensitivity and fairly low specificity for aggressive stenosing or fistulizing phenotypes. However, the presence of two mutations in NOD2 (either homozygous or complex heterozygous) has a high degree of specificity for aggressive disease phenotype, although the sensitivity and AuROC remain poor. The presence of homozygous mutations in NOD2 for p.Leu1007fsX1008 has an even higher degree of specificity for aggressive disease phenotype, although the sensitivity remains poor. These results show that the presence of multiple mutations identifies a particularly high-risk group, although this is a very insensitive prognostic test. In contrast, the presence of single mutations in NOD2 is not a reliable predictor of disease phenotype.

These findings do not minimize the role NOD2 and other genetic mutations have in the development of Crohn's disease. NOD2 has a clear role as a susceptibility gene for the risk of development of Crohn's disease. However, at this point, the ability of NOD2 to predict disease severity is limited to patients with multiple mutant alleles. It is clear that genetics has a key role in the susceptibility to developing Crohn's disease, and likely has a role in disease behavior. The pathophysiology is complex, and the role genetics has is far more nuanced than the presence or absence of one mutation determining a certain disease behavior. More likely, a reliable disease
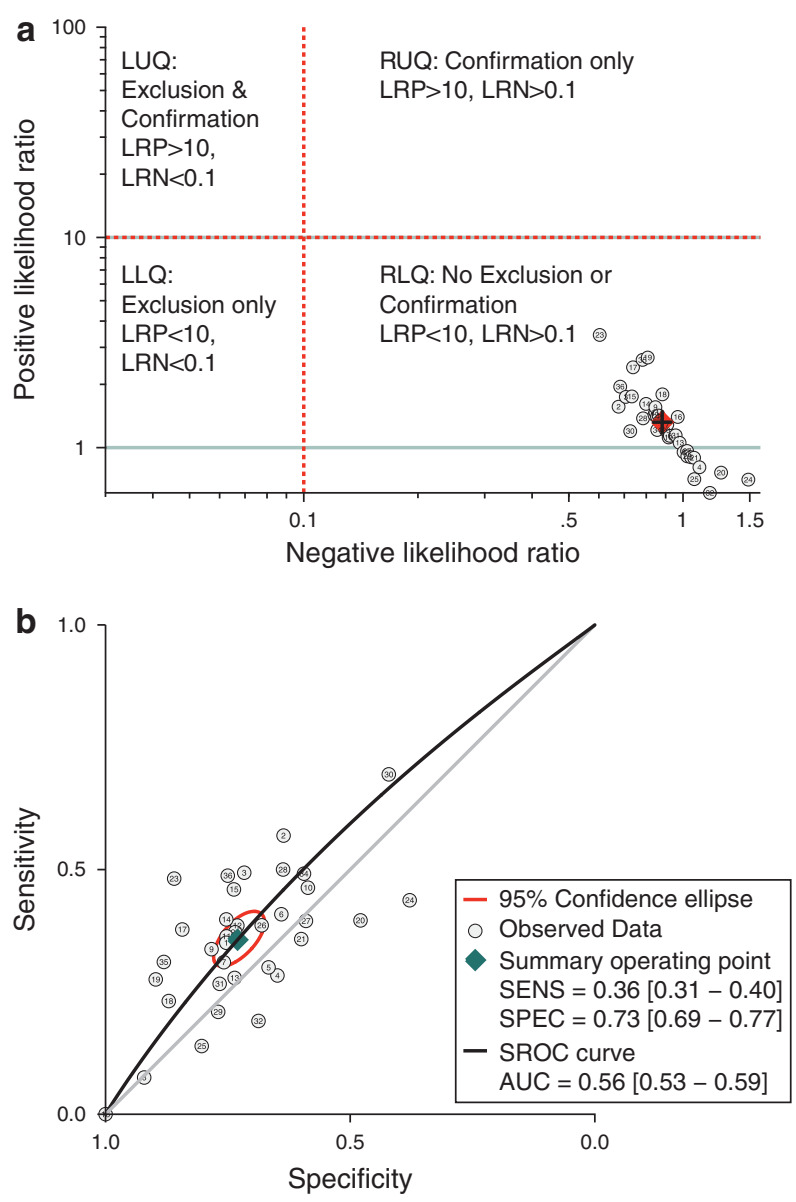

Figure 5. Prognostic accuracy of NOD2 for complicated disease. (a) Likelihood ratio (LR) scatter plot matrix of the presence of any NOD2 mutant alleles associated with complicated disease. The summary LR point is represented by the red diamond. The bars represent $95 \%$ confidence intervals. All studies are in the right lower quadrant providing neither exclusion nor confirmation, demonstrating that NOD2 is a weak predictor of complicated disease phenotype. (b) Summary receiver operating characteristics (sROC) curves for the presence of one or more NOD2 mutant alleles as a predictor of complicated Crohn's disease phenotype. A perfect test has an area under the SROC curve (AuROC) close to 1 , and a poor test has an AuROC close to 0.5. The AuROC curve of 0.56 for complicated disease is consistent with low prognostic accuracy. AUC, area under the curve; LLQ, left lower quadrant; LRN, likelihood ratio negative; LRP, likelihood ratio positive; LUQ, left upper quadrant; NOD2, nucleotidebinding oligomerization domain 2; $R L Q$, right lower quadrant; $R \cup Q$, right upper quadrant; SENS, sensitivity; SPEC, specificity.

phenotype prediction will require a multifactorial approach, which will include environmental factors, genetic factors, medication exposure, smoking, initial clinical presentation, etc.

The findings of this meta-analysis suggest that the presence of two mutant NOD2 alleles is quite specific for future complicated disease. Although the sensitivity is poor and the AuROC is poor, the high degree of specificity may be sufficient to recommend testing for double mutations if we can identify therapies that can truly change the outcomes for this high-risk stratum of patients. Testing for double mutations would likely miss many patients with aggressive disease. However, the presence of double mutations, 
particularly mutations in p.Leu1007fsX1008, does identify a highrisk stratum of reagent-grade patients that should be identified and analyzed as a distinct subgroup in clinical trials. If prospective trials can show a change in outcomes in these patients, this would be a strong justification for targeted top-down therapy in this group of high-risk patients to prevent stricturing or fistulizing complications.

The other major finding of this meta-analysis is the lack of prognostic value of the presence of one mutant allele for predicting Crohn's disease behavior. Although we specifically studied NOD2 mutations, recent genome-wide association studies have identified numerous other genes that contribute to the susceptibility of developing Crohn's disease (44-46). It is likely that the level at which genetics contributes to phenotypic disease expression is complex and multiple risk alleles contribute to complex interactions. Further studies addressing disease behavior will likely require large-scale, multicenter trials to obtain sufficient clinical data to accurately ascertain the cumulative risk from clinical, genetic, and environmental factors. Once additional predictive factors are identified and validated, we will be better able to study targeted therapies in high-risk patients.

\section{CONFLICT OF INTEREST}

Guarantor of the article: Jeremy Adler, MD, MSc.

Specific author contributions: Study and concept design, literature search, data extraction, and statistical analysis: Jeremy Adler; secondary literature search and independent data extraction: Sujal C. Rangwalla; statistical analysis: Ben A. Dwamena; concept development and study design, and third reviewer when consensus could not be reached during data extraction: Peter D.R. Higgins.

Financial support: None.

Potential competing interests: None.

\section{REFERENCES}

1. Louis E, Collard A, Oger AF et al. Behaviour of Crohn's disease according to the Vienna classification: changing pattern over the course of the disease. Gut 2001;49:777-82.

2. Cosnes J, Cattan S, Blain A et al. Long-term evolution of disease behavior of Crohn's disease. Inflamm Bowel Dis 2002;8:244-50.

3. Morimoto N, Kato J, Kuriyama M et al. Risk factors and indications for first surgery in Crohn's disease patients. Hepatogastroenterology 2007;54: 2011-6.

4. Tremaine WJ, Timmons LJ, Loftus EV Jr et al. Age at onset of inflammatory bowel disease and the risk of surgery for non-neoplastic bowel disease. Aliment Pharmacol Ther 2007;25:1435-41.

5. Beaugerie L, Seksik P, Nion-Larmurier I et al. Predictors of Crohn's disease. Gastroenterology 2006;130:650-6.

6. Gasche C, Scholmerich J, Brynskov J et al. A simple classification of Crohn's disease: report of the Working Party for the World Congresses of Gastroenterology, Vienna 1998. Inflamm Bowel Dis 2000;6:8-15.

7. Hampe J, Cuthbert A, Croucher PJ et al. Association between insertion mutation in NOD2 gene and Crohn's disease in German and British populations. Lancet 2001;357:1925-8.

8. Hugot JP, Chamaillard M, Zouali $\mathrm{H}$ et al. Association of NOD2 leucine-rich repeat variants with susceptibility to Crohn's disease. Nature 2001;411: 599-603.

9. Ogura $\mathrm{Y}$, Bonen DK, Inohara $\mathrm{N}$ et al. A frameshift mutation in NOD2 associated with susceptibility to Crohn's disease. Nature 2001;411:603-6.

10. Abreu MT, Taylor KD, Lin YC et al. Mutations in NOD2 are associated with fibrostenosing disease in patients with Crohn's disease. Gastroenterology 2002;123:679-88.
11. Nunez C, Barreiro M, Dominguez-Munoz JE et al. CARD15 mutations in patients with Crohn's disease in a homogeneous Spanish population. Am J Gastroenterol 2004;99:450-6.

12. Barrett JC, Hansoul S, Nicolae DL et al. Genome-wide association defines more than 30 distinct susceptibility loci for Crohn's disease. Nat Genet 2008;40:955-62.

13. Alvarez-Lobos M, Arostegui JI, Sans M et al. Crohn's disease patients carrying Nod2/CARD15 gene variants have an increased and early need for first surgery due to stricturing disease and higher rate of surgical recurrence. Ann Surg 2005;242:693-700.

14. Annese V, Lombardi G, Perri F et al. Variants of CARD15 are associated with an aggressive clinical course of Crohn's disease-an IG-IBD study. Am J Gastroenterol 2005;100:84-92.

15. Helio T, Halme L, Lappalainen M et al. CARD15/NOD2 gene variants are associated with familially occurring and complicated forms of Crohn's disease. Gut 2003;52:558-62.

16. Russell RK, Drummond HE, Nimmo EE et al. Genotype-phenotype analysis in childhood-onset Crohn's disease: NOD2/CARD15 variants consistently predict phenotypic characteristics of severe disease. Inflamm Bowel Dis 2005;11:955-64.

17. Roesler J, Thurigen A, Sun L et al. Influence of CARD15 mutations on disease activity and response to therapy in 65 pediatric $\mathrm{Crohn}$ patients from Saxony, Germany. J Pediatr Gastroenterol Nutr 2005;41:27-32.

18. Jurgens M, Brand S, Laubender RP et al. The presence of fistulas and NOD2 homozygosity strongly predict intestinal stenosis in Crohn's disease independent of the IL23R genotype. J Gastroenterol 2010;45:721-31.

19. Baptista ML, Amarante H, Picheth G et al. CARD15 and IL23R influences Crohn's disease susceptibility but not disease phenotype in a Brazilian population. Inflamm Bowel Dis 2008;14:674-9.

20. Louis E, Michel V, Hugot JP et al. Early development of stricturing or penetrating pattern in Crohn's disease is influenced by disease location, number of flares, and smoking but not by NOD2/CARD15 genotype. Gut 2003;52:552-7.

21. Ince AT, Hatirnaz O, Ovunc O et al. 1007fs, G908R, R702W mutations and P268S, IVS8(+158) polymorphisms of the CARD15 gene in Turkish inflammatory bowel disease patients and their relationship with disease-related surgery. Dig Dis Sci 2008;53:1683-92.

22. Economou M, Trikalinos TA, Loizou KT et al. Differential effects of NOD2 variants on Crohn's disease risk and phenotype in diverse populations: a metaanalysis. Am J Gastroenterol 2004;99:2393-404.

23. Vavassori P, Borgiani P, Biancone L et al. CARD15 mutation analysis in an Italian population: Leu1007fsinsC but neither Arg702Trp nor Gly908Arg mutations are associated with Crohn's disease. Inflamm Bowel Dis 2004;10:116-21.

24. Lesage S, Zouali H, Cezard JP et al. CARD15/NOD2 mutational analysis and genotype-phenotype correlation in 612 patients with inflammatory bowel disease. Am J Hum Genet 2002;70:845-57.

25. Barker FG II, Carter BS. Synthesizing medical evidence: systematic reviews and metaanalyses. Neurosurg Focus 2005;19:E5.

26. Deville WL, Buntinx F, Bouter LM et al. Conducting systematic reviews of diagnostic studies: didactic guidelines. BMC Med Res Methodol 2002;2:9.

27. Moher D, Cook DJ, Eastwood S et al. Improving the quality of reports of meta-analyses of randomised controlled trials: the QUOROM statement. Quality of Reporting of Meta-analyses. Lancet 1999;354:1896-900.

28. Stroup DF, Berlin JA, Morton SC et al. Meta-analysis of observational studies in epidemiology: a proposal for reporting. Meta-analysis Of Observational Studies in Epidemiology (MOOSE) Group. JAMA 2000;283: 2008-12.

29. van der Weijden T, IJzermans CJ, Dinant GJ et al. Identifying relevant diagnostic studies in MEDLINE. The diagnostic value of the erythrocyte sedimentation rate (ESR) and dipstick as an example. Fam Pract 1997;14:204-8.

30. Silverberg MS, Satsangi J, Ahmad T et al. Toward an integrated clinical, molecular and serological classification of inflammatory bowel disease: Report of a Working Party of the 2005 Montreal World Congress of Gastroenterology. Can J Gastroenterol 2005;19 (Suppl A): 5-36.

31. Leeflang MM, Deeks JJ, Gatsonis C et al. Systematic reviews of diagnostic test accuracy. Ann Intern Med 2008;149:889-97.

32. Reitsma JB, Glas AS, Rutjes AW et al. Bivariate analysis of sensitivity and specificity produces informative summary measures in diagnostic reviews. J Clin Epidemiol 2005;58:982-90.

33. Swets JA. Measuring the accuracy of diagnostic systems. Science 1988;240:1285-93.

34. Glas AS, Lijmer JG, Prins MH et al. The diagnostic odds ratio: a single indicator of test performance. J Clin Epidemiol 2003;56:1129-35. 
35. Higgins JP, Thompson SG, Deeks JJ et al. Measuring inconsistency in meta-analyses. BMJ 2003;327:557-60.

36. Dwamena BA. Meta-Analytic Depiction of Ordered Categorical Diagnostic Test Accuracy in ROC Space 2009. Stata Users Group DC09 Stata Conference. http://ideas.repec.org/p/boc/dcon09/3.html; http://www.stata. com/meeting/dcconf09/abstracts.html.

37. Dwamena BA. MIDAS: Stata Module for Meta-Analytical Integration of Diagnostic Test Accuracy Studies, 2007. Statistical Software Components \# S456880. Boston College Department of Economics. http://ideas.repec. org/c/boc/bocode/s456880.html.

38. Seiderer J, Schnitzler F, Brand S et al. Homozygosity for the CARD15 frameshift mutation 1007fs is predictive of early onset of Crohn's disease with ileal stenosis, entero-enteral fistulas, and frequent need for surgical intervention with high risk of re-stenosis. Scand J Gastroenterol 2006;41:1421-32.

39. Mardini HE, Gregory KJ, Nasser M et al. Gastroduodenal Crohn's disease is associated with NOD2/CARD15 gene polymorphisms, particularly L1007P homozygosity. Dig Dis Sci 2005;50:2316-22.

40. Crawford NP, Colliver DW, Eichenberger MR et al. CARD15 genotypephenotype relationships in a small inflammatory bowel disease population with severe disease affection status. Dig Dis Sci 2007;52: 2716-24.

41. Chua KH, Hilmi I, Ng CC et al. Identification of NOD2/CARD15 mutations in Malaysian patients with Crohn's disease. J Dig Dis 2009;10:124-30.

42. Oostenbrug LE, Nolte IM, Oosterom E et al. CARD15 in inflammatory bowel disease and Crohn's disease phenotypes: an association study and pooled analysis. Dig Liver Dis 2006;38:834-45.

43. Murillo LS, Morre SA, Pena AS. Role of the CARD15 gene in the pathogenesis of Crohn disease: phenotypic classification and prognostic implications. Scand J Gastroenterol 2003;38:1107-14.

44. van Heel DA, Fisher SA, Kirby A et al. Inflammatory bowel disease susceptibility loci defined by genome scan meta-analysis of 1952 affected relative pairs. Hum Mol Genet 2004;13:763-70.

45. Wang $\mathrm{K}$, Zhang $\mathrm{H}$, Kugathasan $\mathrm{S}$ et al. Diverse genome-wide association studies associate the IL12/IL23 pathway with Crohn disease. Am J Hum Genet 2009;84:399-405.

46. Mathew CG. New links to the pathogenesis of Crohn disease provided by genome-wide association scans. Nat Rev Genet 2008;9:9-14.

47. Ahmad T, Armuzzi A, Bunce $\mathrm{M}$ et al. The molecular classification of the clinical manifestations of Crohn's disease. Gastroenterology 2002;122:854-66.

48. Alvarez-Lobos M, Arostegui JI, Sans M et al. Combined type-1 plasminogen activator inhibitor and NOD2/CARD15 genotyping predicts complicated Crohn's disease behaviour. Aliment Pharmacol Ther 2007;25:429-40.

49. Annese V, Lombardi G, Perri F et al. Variants of CARD 15 are associated with an aggressive clinical course of Crohn's disease-an IG-IBD study. Am J Gastroenterol 2005;100:84-92.

50. Brant SR, Picco MF, Achkar JP et al. Defining complex contributions of NOD2/CARD15 gene mutations, age at onset, and tobacco use on Crohn's disease phenotypes. Inflamm Bowel Dis 2003;9:281-9.

51. Bianchi V, Maconi G, Ardizzone S et al. Association of NOD2/CARD15 mutations on Crohn's disease phenotype in an Italian population. Eur J Gastroenterol Hepatol 2007;19:217-23.

52. Buning C, Genschel J, Buhner S et al. Mutations in the NOD2/CARD15 gene in Crohn's disease are associated with ileocecal resection and are a risk factor for reoperation. Aliment Pharmacol Ther 2004;19:1073-8.

53. Canto E, Ricart E, Busquets D et al. Influence of a nucleotide oligomerization domain 1 (NOD1) polymorphism and NOD2 mutant alleles on Crohn's disease phenotype. World J Gastroenterol 2007;13:5446-53

54. Cucchiara S, Latiano A, Palmieri O et al. Role of CARD15, DLG5 and OCTN genes polymorphisms in children with inflammatory bowel diseases. W J Gastroenterol 2007;13:1221-9.

55. Cukovic-Cavka S, Vermeire S, Hrstic I et al. NOD2/CARD15 mutations in Croatian patients with Crohn's disease: prevalence and genotype-phenotype relationship. Eur J Gastroenterol Hepatol 2006;18:895-9.

56. Dassopoulos T, Nguyen GC, Talor MV et al. NOD2 mutations and antisaccharomyces cerevisiae antibodies are risk factors for Crohn's disease in African Americans. Am J Gastroenterol 2009;105:378-86.

57. De Diego C, Alcantara M, Valle J et al. Frequency of CARD15 polymorphisms in patients with Crohn's disease from Toledo, Spain: genotypephenotype correlation. Genetic Testing 2006;10:178-85.
58. de Ridder L, Weersma RK, Dijkstra G et al. Genetic susceptibility has a more important role in pediatric-onset Crohn's disease than in adult-onset Crohn's disease. Inflamm Bowel Dis 2007;13:1083-92.

59. Esters N, Pierik M, van Steen K et al. Transmission of CARD15 (NOD2) variants within families of patients with inflammatory bowel disease. Am J Gastroenterol 2004;99:299-305.

60. Fernandez L, Mendoza JL, Martinez A et al. IBD1 and IBD3 determine location of Crohn's disease in the Spanish population. Inflamm Bowel Dis 2004;10:715-22.

61. Ferreira AC, Almeida S, Tavares M et al. NOD2/CARD15 and TNFA, but not IL1B and IL1RN, are associated with Crohn's disease. Inflamm Bowel Dis 2005;11:331-9.

62. Fidder HH, Olschwang S, Avidan B et al. Association between mutations in the CARD15 (NOD2) gene and Crohn's disease in Israeli Jewish patients. Am J Med Genet 2003;121A:240-4.

63. Giachino D, van Duist MM, Regazzoni S et al. Analysis of the CARD15 variants R702W, G908R and L1007fs in Italian IBD patients. Eur J Hum Genet 2004;12:206-12.

64. Heresbach D, Gicquel-Douabin V, Birebent B et al. NOD2/CARD15 gene polymorphisms in Crohn's disease: a genotype-phenotype analysis. Eur J Gastroenterol Hepatol 2004;16:55-62.

65. Hsiao CH, Wei SC, Wong JM et al. Pediatric Crohn disease: clinical and genetic characteristics in Taiwan. J Pediatr Gastroenterol Nutr 2007;44:342-6.

66. Laghi L, Costa S, Saibeni S et al. Carriage of CARD15 variants and smoking as risk factors for resective surgery in patients with Crohn's ileal disease. Aliment PharmacolTher 2005;22:557-64.

67. Lakatos PL, Lakatos L, Szalay F et al. Toll-like receptor 4 and NOD2/CARD15 mutations in Hungarian patients with Crohn's disease: phenotype-genotype correlations. W J Gastroenterol 2005; 11:1489-95.

68. Lappalainen M, Paavola-Sakki P, Halme L et al. Novel CARD15/NOD2 mutations in Finnish patients with Crohn's disease and their relation to phenotypic variation in vitro and in vivo. Inflamm Bowel Dis 2008; 14:176-85.

69. Linskens RK, Mallant-Hent RC, Murillo LS et al. Genetic and serological markers to identify phenotypic subgroups in a Dutch Crohn's disease population. Dig Liver Dis 2004;36:29-34.

70. Louis E, Michel V, Hugot JP et al. Early development of stricturing or penetrating pattern in Crohn's disease is influenced by disease location, number of flares, and smoking but not by NOD2/CARD15 genotype [see comment]. Gut 2003;52:552-7.

71. Maconi G, Colombo E, Sampietro GM et al. CARD15 gene variants and risk of reoperation in crohn's disease patients. Am J Gastroenterol 2009;104:2483-91.

72. Marrakchi R, Bougatef K, Moussa A et al. 3020insC insertion in NOD2/ CARD15 gene, a prevalent variant associated with anti-Saccharomyces cerevisiae antibodies and ileal location of Crohn's disease in Tunisian population. Inflamm Res 2009;58:218-23.

73. Mendoza JL, Murillo LS, Fernandez L et al. Prevalence of mutations of the NOD2/CARD15 gene and relation to phenotype in Spanish patients with Crohn disease. Scand J Gastroenterol 2003;38:1235-40.

74. Protic MB, Pavlovic ST, Bojic DZ et al. CARD15 gene polymorphisms in Serbian patients with Crohn's disease: genotype-phenotype analysis. Eur J Gastroenterol Hepatol 2008;20:978-84.

75. Radlmayr M, Torok HP, Martin K et al. The c-insertion mutation of the NOD2 gene is associated with fistulizing and fibrostenotic phenotypes in Crohn's disease. Gastroenterology 2002;122:2091-2.

76. Rigoli L, Romano C, Caruso RA et al. Clinical significance of NOD2/ CARD15 and Toll-like receptor 4 gene single nucleotide polymorphisms in inflammatory bowel disease. World J Gastroenterol 2008;14:4454-61.

77. Rodrigo L, Martinez-Borra J, Garrote JA et al. [CARD15 mutations are poorly related to Crohn's disease phenotypes in Asturias]. Rev Esp Enferm Dig 2007;99:570-757.

78. Sabate JM, Ameziane N, Lamoril J et al. The V249I polymorphism of the CX3CR1 gene is associated with fibrostenotic disease behavior in patients with Crohn's disease. Eur J Gastroenterol Hepatol 2008;20:748-55.

79. Schoepfer AM, Schaffer T, Mueller S et al. Phenotypic associations of Crohn's disease with antibodies to flagellins A4-Fla2 and Fla-X, ASCA, pANCA, PAB, and NOD2 mutations in a Swiss Cohort. Inflamm Bowel Dis 2009; 15:1358-67.

80. Shaoul R, Karban A, Reif S et al. Disease behavior in children with Crohn's disease: the effect of disease duration, ethnicity, genotype, and phenotype. Dig Dis Sci 2009;54:142-50. 
81. Smith BR, Arnott ID, Drummond HE et al. Disease location, anti-Saccharomyces cerevisiae antibody, and NOD2/CARD15 genotype influence the progression of disease behavior in Crohn's disease. Inflamm Bowel Dis 2004;10:521-8.

82. Sun L, Roesler J, Rosen-Wolff A et al. CARD15 genotype and phenotype analysis in 55 pediatric patients with Crohn disease from Saxony, Germany. J Pediatr Gastroenterol Nutr 2003;37:492-7.

83. Tekin F, Berdeli A, Ozutemiz O et al. Evaluation of the association of NOD2/CARD15 gene polymorphisms with clinical course of Turkish Crohn's disease patients. Int J Med Med Sci 2009;1:211-4.

84. Tomer G, Ceballos C, Concepcion E et al. NOD2/CARD15 variants are associated with lower weight at diagnosis in children with Crohn's disease. Am J Gastroenterol 2003;98:2479-84.
85. Torkvist L, Noble CL, Lordal M et al. Contribution of CARD15 variants in determining susceptibility to Crohn's disease in Sweden. Scand J Gastroenterol 2006;41:700-5.

86. van der Linde K, Boor PP, Houwing-Duistermaat JJ et al. CARD15 mutations in Dutch familial and sporadic inflammatory bowel disease and an overview of European studies. Eur J Gastroenterol Hepatol 2007;19:449-59.

87. Vermeire S, Wild G, Kocher K et al. CARD15 genetic variation in a Quebec population: prevalence, genotype-phenotype relationship, and haplotype structure. Am J Hum Genet 2002;71:74-83.

88. Vind I, Vieira A, Hougs L et al. NOD2/CARD15 gene polymorphisms in Crohn's disease: a genotype-phenotype analysis in Danish and Portuguese patients and controls. Digestion 2005;72:156-63. 